\title{
Cianoacrilato como protetor superficial de restaurações de cimento de óxido de zinco e eugenol e de cimento de ionômero de vidro: avaliação da infiltração marginal Cyanoacrylate as a surface protector for zinc oxide-eugenol cement and glass ionomer cement restorations: assessment of marginal infiltration
}

\section{Fernanda de Carvalho Panzeri PIRES-DE-SOUZA}

Docente - Departamento de Materiais Dentários e Prótese - Faculdade de Odontologia de Ribeirão Preto Universidade de São Paulo - USP - Ribeirão Preto - SP - Brasil

\section{Marta Maria Martins Giamatei CONTENTE}

Aluna de Graduação - Faculdade de Odontologia de Ribeirão Preto - Universidade de São Paulo - USP - Ribeirão Preto - SP - Brasil

\section{Luciana Assirati CASEMIRO}

Pós-doutoranda - Departamento de Materiais Dentários e Prótese - Faculdade de Odontologia de Ribeirão Preto Universidade de São Paulo - USP - Ribeirão Preto - SP - Brasil

\begin{abstract}
Resumo
O objetivo deste trabalho foi avaliar a infiltração marginal em restaurações de cimento de óxido de zinco e eugenol e cimento de ionômero de vidro com e sem a utilização de um selante de superfície à base de cianoacrilato. Trinta dentes posteriores foram restaurados com cimento de óxido de zinco e eugenol, OZE, (15) ou com cimento de ionômero de vidro, CIV, (15). Para cada material, os dentes foram divididos em grupo controle (5), proteção superficial com cianoacrilato precedida de ataque ácido (5) e proteção superficial com cianoacrilato sem ataque ácido. Após ensaio de termociclagem, as superfícies radiculares dos dentes foram isoladas com Araldite ${ }^{\circledR}$ e as amostras imersas em solução corante Rodamina B $0,2 \%$. As amostras foram acondicionadas em estufa a $37^{\circ} \mathrm{C}$ por 24 horas e, a seguir, removidas da solução corante e lavadas em água corrente. Os dentes foram embutidos em resina de poliéster e cortados no sentido mésio-distal em seu longo eixo. O grau de penetração marginal foi avaliado por meio de microscopia óptica segundo escore previamente definido e os resultados obtidos analisados estatisticamente (Kruskal-Wallis $\mathrm{p}<0.05$ ). As restaurações de OZE apresentaram infiltração marginal reduzida quando submetidas à proteção superficial com cianoacrilato após realização do ataque ácido. O cianoacrilato não reduziu a infiltração marginal das restaurações de CIV (Apoio PIBIC/CNPq).
\end{abstract}

\section{UNITERMOS}

Cianoacrilatos; selantes de fossas e fissuras; cimento de óxido de zinco e eugenol; cimentos de ionômeros de vidro; materiais dentários, estudo comparativo

\section{INTRODUÇÃo}

A prevenção de patologias, o alívio da dor, a melhora da eficiência mastigatória, da fonação ou da estética tem sido as principais metas a serem alcançadas no tratamento odontológico. Para que esses objetivos sejam atingidos, há uma busca incessante dos pesquisadores em desenvolver e aprimorar materiais dentários biocompatíveis e capazes de suportar as condições adversas do meio bucal (ANUSAVICE, ${ }^{2}$ 1998).

No processo de restauração de dentes cariados ou com restaurações fraturadas, a primeira etapa consiste na adequação do meio bucal, cujo objetivo é promover uma mudança de hábitos por parte do paciente e remover os fatores ou nichos que favorecem a retenção de biofilme, tais como cavidades abertas e restaurações deficientes. Além disso, esse procedimento proporciona a proteção do órgão pulpar, a paralisação da progressão da lesão e a diminuição dos focos de infecção (ARAÚJO \& FIGUEIREDO, ${ }^{3}$ 1999). Para o selamento dessas cavidades, são utilizados materiais restauradores como o cimento de óxido de zinco e eugenol, que possui excelentes propriedades sedativas e o cimento de ionômero de vidro, cujas principais vantagens são a adesão à estrutura dental e a liberação de flúor.

Em algumas situações, essas restaurações necessitam permanecer por um longo tempo na cavidade bucal, num ambiente adverso e exigente em relação às propriedades físicas, mecânicas e biológicas dos materiais empregados. Exemplifica essa condição o uso de curativos expectantes, cujo prazo médio de permanência é de 45 dias $^{35}$, período em que as restaurações temporárias devem se manter íntegras. 
A desintegração no meio bucal é uma condição freqüentemente encontrada nas restaurações provisórias de cimento de óxido de zinco e eugenol. $\mathrm{O}$ eugenolato de zinco, resultado da reação entre o óxido de zinco e o eugenol, possui baixa estabilidade; o equilíbrio entre o eugenol e o óxido de zinco contidos no cimento é desestabilizado quando o eugenol é removido. Conseqüentemente, a matriz se hidrolisa continuamente em eugenol e hidróxido de zinco, fazendo com que o cimento perca resistência mecânica e se desintegre (WILSON \& BATCHELOR, ${ }^{35}$ 1970). Com isso, pode haver a entrada de microrganismos entre o dente e a restauração, o que se caracterizaria como a microinfiltração. A infecção causada por essa infiltração microbiana em torno da restauração constitui uma ameaça à polpa muito maior que a própria toxicidade do material restaurador (BRÄNNSTROM \& NYBORG.. ${ }^{11} 1971$, COX et al. ${ }^{16}$ 1987).

Na tentativa de aumentar a durabilidade das restaurações, reduzindo sua solubilidade e desgaste, tem sido preconizado o uso de selantes de superfície (DICKINSON et al. ${ }^{17}$ 1990). Sua aplicação proporciona o selamento dos poros do material e o vedamento da interface dente/restauração, cuja abertura favorece o início do processo de infiltração marginal. Em sua maioria, os selantes de superfície são resinas fluidas e com grande capacidade de escoamento, para facilitar a penetração nas irregularidades, entretanto, esmalte de unha e cianoacrilato são também substâncias propostas para esta finalidade (GUZMAN-ARMSTRONG \& MITCHELL, ${ }^{20}$ 2002).

O cianoacrilato foi desenvolvido em 1957 por Coover \& Shearer (BHASKAR \& FRISCH, ${ }^{7}$ 1968) e possui como principal vantagem a capacidade de adesão aos tecidos vivos e materiais, mesmo em presença de umidade (HEROD ${ }^{21}$ 1990; MONTANARO et al. ${ }^{29}$ 2001). A partir da década de 1960 foram propostas várias aplicações odontológicas para o cianoacrilato, pode-se citar seu uso como sutura química de tecidos em cirurgia, (QUINN et al. ${ }^{32}$ 1997; MESSI \& MARCHI, ${ }^{27}$ 1992; BOCCA et al. ${ }^{9}$ 1999; PEREZ et al. ${ }^{31}$ 2000; KULKARNI \& CHAVA, ${ }^{24}$ 2003) e periodontia (GRISDALE, ${ }^{19}$ 1998), para colagem de brackets ortodônticos (AJLOUNI et al. ${ }^{1}$ 2004; BISHARA et al. ${ }^{8}$ 2005), como dessensibilizante (USUMEZ et al..$^{34}$ 2004), no tratamento da permeabilidade dentinária (LOPES-SILVA \& LAGE-MARQUES, ${ }^{26}$ 2003), em cimentação de prótese parcial fixa (LAMBERT, ${ }^{25}$ 1975; BARLATTANI et al. ${ }^{6}$ 1991) e no tratamento endodôntico (CHONG et al. ${ }^{13}$ 1995; FIREDMAN et al. ${ }^{18}$ 1993; BARKHORDAR et al., ${ }^{5}$ 1988). Outras aplica- ções avaliadas foram o uso como agentes temporários de cobertura de resinas acrílicas, para promoção de lisura superficial (BORCHERS et al. ${ }^{10}$ 1999) e como agentes de cobertura para superfícies de modelos de gesso (CAMPAGNI et al. ${ }^{13}$ 1986).

Apesar da toxicidade dos cianoacrilatos terem sido relatadas (THUMWANIT \& KEDJARUNE, ${ }^{33}$ 1999), estes são considerados seguros para o uso médico e odontológico (AZEVEDO et al. ${ }^{4}$ 2003; MORINAGA et al. ${ }^{30}$ 2003).

Diante da possibilidade de utilização de um selante de superfície sobre restaurações como forma de aumentar a longevidade das restaurações, este trabalho teve como objetivo mensurar a infiltração marginal em restaurações de cimento de óxido de zinco e eugenol e cimento de ionômero de vidro com e sem a utilização de um selante de superfície à base de cianoacrilato.

\section{Material e Método}

Previamente, o projeto foi submetido ao Comitê de Ética da Faculdade de Odontologia de Ribeirão Preto - FORP - USP, tendo recebido aprovação sob o número 2003.1.409.58.2.

Em trinta dentes posteriores hígidos foram confeccionadas cavidades classe I ( $4 \mathrm{~mm}$ no sentido mésio-distal, $3 \mathrm{~mm}$ no sentido vestíbulo-lingual e $2 \mathrm{~mm}$ de profundidade), com brocas tronco-cônicas n 245 (KG Sorensen, Barueri, SP, Brasil) acionadas em alta rotação e com refrigeração abundante (água). Em seguida, 15 dentes de cada grupo foram restaurados com cimento de óxido de zinco e eugenol reforçado (IRM, Dentsply, Petrópolis, RJ, Brasil) e os outros 15 com cimento de ionômero de vidro (Vidrion R, SSWhite, Rio de Janeiro, RJ, Brasil).

Os materiais foram manipulados de acordo com as recomendações dos fabricantes. Sobre uma placa de vidro foi proporcionada uma medida de pó para cada gota do líquido que compõem o cimento de óxido de zinco e eugenol. Em seguida, com o auxílio de uma espátula 24 , o pó foi incorporado lentamente ao líquido, seguido de manipulação vigorosa até que todo o pó fosse incorporado e uma massa fosse obtida.

Para o cimento de ionômero de vidro, também uma porção de pó foi dosada para cada gota de líquido a ser utilizada. Em seguida, com o auxílio de uma espátu$\mathrm{la}^{22}$, o pó foi aglutinado ao líquido com movimentos suaves, utilizando-se para isso um tempo total de 45 segundos.

Os grupos experimentais estão apresentados na Quadro 1, sendo os grupos 1 e 4 considerados con- 
troles do material IRM e Vidrion R, respectivamente. Quando indicado, foi empregado o ácido fosfórico a $37 \%$ por 15 segundos na superfície oclusal dos dentes, seguido de lavagem com spray ar/água por 30s e secagem com ar por 20s. O cianoacrilato (Super
Bonder, Henkel Ltda., Itapevi, SP, Brasil) foi aplicado com pincel em duas camadas, aguardando-se a secagem do material entre elas. Essa aplicação iniciou-se imediatamente após a presa dos materiais restauradores.

\section{Quadro 1 - Grupos experimentais}

\begin{tabular}{|c|c|c|}
\hline Grupo & Material Restaurador & Procedimento \\
\hline 1 & \multirow{3}{*}{ OZE } & Sem proteção - controle \\
\hline 2 & & Proteção com cianoacrilato \\
\hline 3 & & Ataque ácido + proteção com cianoacrilato \\
\hline 4 & \multirow{3}{*}{ CIV } & Sem proteção - controle \\
\hline 5 & & Proteção com cianoacrilato \\
\hline 6 & & Ataque ácido + proteção com cianoacrilato \\
\hline
\end{tabular}

Após a aplicação da segunda camada do cianoacrilato, os dentes foram submetidos ao ensaio de termociclagem em Máquina de Simulação de Ciclos Térmicos (Modelo MSCT-3, São Carlos, Brasil), realizando-se 1500 ciclos de 60 s cada, com temperaturas de 5 e $55^{\circ} \mathrm{C}$. A seguir, toda a área radicular e coronária, respeitando o limite de $1 \mathrm{~mm}$ em relação à área restaurada, foram isoladas com resina epóxica (Araldite®, Brascola Ltda, São Bernardo do Campo, SP, Brasil). A finalidade deste procedimento foi garantir que a solução corante não penetraria no dente senão pelas margens da restauração. As amostras foram imersas em solução de Rodamina B a 0,2\%, pH 7,0 (Carlo Erva Reagenti, Limito, Milão, Itália) e armazenadas em estufa (37\% $24 \mathrm{~h})$. Em seguida, foram lavadas em água corrente por 60 segundos. Os dentes foram embutidos em resina de poliéster (Milflex, São Paulo, SP, Brasil) e cortados no sentido mésio-distal em seu longo eixo, com máquina de corte (Minitrom, Struers, Alemanha) e velocidade de 400rpm.

O grau de penetração marginal foi avaliado segundo um escore previamente definido (CORONA et al. ${ }^{15}$ 2001) (Quadro 2), com auxílio de microscópio óptico (Nikon, Japan).

\section{Quadro 2 - Escores para avaliação da penetração marginal do corante}

\begin{tabular}{|c|c|}
\hline Escore & Ocorrência \\
\hline 0 & Sem infiltração \\
\hline 1 & Penetração apenas em esmalte, no máximo até o limite da junção amelodentinária \\
\hline 2 & Penetração em dentina atingindo no máximo a metade da distância compreendida \\
entre a junção amelodentinária e a polpa
\end{tabular}


CIANOACRILATO COMO PROTETOR SUPERFICIAL DE RESTAURAÇÕES DE CIMENTO DE ÓXIDO DE ZINCO E EUGENOL

E DE CIMENTO DE IONÔMERO DE VIDRO: AVALIAÇÃO DA INFILTRAÇÃO MARGINAL

\section{Resultados}

Os resultados obtidos podem ser visualizados na Tabela 1; na Tabela 2 estão apresentados os resultados da análise estatística (Teste de Kruskal-Walis, p<0,05).

Tabela 1 - Resultados da penetração marginal da solução de corante segundo escore definido

\begin{tabular}{c|c|c|c}
\hline \multirow{3}{*}{ Material } & Controle & $\begin{array}{c}\text { Cianoacrilato sem } \\
\text { ataque ácido }\end{array}$ & $\begin{array}{c}\text { Cianoacrilato com } \\
\text { ataque ácido }\end{array}$ \\
\hline \multirow{4}{*}{ OZE } & 3 & 3 & 0 \\
\cline { 2 - 4 } & 3 & 3 & 1 \\
\cline { 2 - 4 } & 3 & 3 & 0 \\
\cline { 2 - 4 } & 3 & 2 & 0 \\
\hline \multirow{5}{*}{ CIV } & 3 & 1 & 1 \\
\cline { 2 - 4 } & 1 & 1 & 1 \\
\cline { 2 - 4 } & 1 & 1 & 1 \\
\cline { 2 - 4 } & 1 & 0 & 1 \\
\cline { 2 - 4 } & 1 & 1 & 1 \\
\hline
\end{tabular}

Tabela 2 - Análise estatística das médias de penetração de corantes segundo escore utilizado (Kruskal-Wallis, $p<0,05)$

\begin{tabular}{c|c|c|c|}
\hline Material & Controle & $\begin{array}{c}\text { Cianoacrilato sem } \\
\text { ataque ácido }\end{array}$ & $\begin{array}{c}\text { Cianoacrilato com } \\
\text { ataque ácido }\end{array}$ \\
\hline OZE & $3,0 \mathrm{a}, \mathrm{A}$ & $2,4 \mathrm{a}, \mathrm{A}$ & $0,2 \mathrm{~b}, \mathrm{~A}$ \\
\hline CIV & $1,0 \mathrm{a}, \mathrm{A}$ & $0,8 \mathrm{a}, \mathrm{A}$ & $1,0 \mathrm{a}, \mathrm{A}$ \\
\hline
\end{tabular}

OZE - cimento de óxido de zinco e eugenol. CIV - Cimento de Ionômero de Vidro. Letras iguais, minúsculas na linha e maiúsculas na coluna, indicam não significância estatística; letras diferentes indicam significância estatística $-\mathrm{p}<0,05$

Os valores de penetração marginal da solução de corante foram bastante variados. A menor infiltração ocorreu nas restaurações temporárias realizadas com cimento de óxido de zinco e eugenol reforçado (IRM, Dentsply) submetidas ao ataque ácido previamente à aplicação do cianoacrilato. As restaurações realizadas com cimento de ionômero de vidro (Vidrion $\mathrm{R}$, SSWhite), não sofreram variação na infiltração marginal quando protegidas ou não por cianoacrilato.

\section{Discussão}

Selar a interface dente/restauração constitui um desafio do tratamento restaurador, uma vez que a penetração de microrganismos sob o material constitui uma agressão ao tecido pulpar mais significativa que a proporcionada pelo próprio material restaurador (BRÄNNSTROM \& NYBORG,${ }^{11} 1971$; COX et al. ${ }^{16}$ 1987). Além disso, decorrem da falta de selamento a 
sensibilidade pós-operatória, a recidiva de cárie e a pigmentação (ANUSAVICE², 1998).

Proteger a superfície de restaurações como forma de aumentar sua longevidade tem sido uma tendência atual (DICKINSON et al. ${ }^{17}$ 1990; GUZMAN-ARMSTRONG \& MITCHELL $\left.{ }^{20}, 2002\right)$. Nesse sentido, avaliar a capacidade do cianoacrilato em prevenir a infiltração marginal em restaurações de cimento de óxido de zinco e eugenol e de ionômero de vidro, materiais amplamente utilizados em odontologia restauradora e preventiva, foi a proposta deste trabalho.

A metodologia empregada visa medir a infiltração marginal na interface dente/restauração. Esta pode ser um meio de se predizer aproximadamente $o$ comportamento do material sob condições clínicas. $\mathrm{O}$ estresse térmico provocado pelas variações cíclicas de temperatura da termociclagem pode simular algumas condições presentes no complexo meio bucal, porém deve ser considerado que nem todas as variáveis clínicas são contempladas pelos experimentos in vitro. Os resultados obtidos com as restaurações de cimento de óxido de zinco e eugenol protegidas com o cianoacrilato precedido de ataque ácido demonstram que a proteção foi eficaz na redução da infiltração marginal, sendo essa diminuição significante estatisticamente $(\mathrm{p}<0,05)$. Isso pode ser explicado pois, nessa condição, acredita-se que o ácido possa criar microretenções na margem da restauração, na interface dente/material restaurador, diminuindo a energia de superfície do esmalte dental favorecendo o escoamento do cianoacrilato e seu embricamento mecânico. Para o grupo controle e 2 (aplicação de cianoacrilato sem ataque ácido prévio) não houve redução estatisticamente significante no grau de infiltração marginal. No grupo 2, possivelmente, houve a eliminação do cianoacrilato e posteriormente da proteção das margens da restauração durante o ensaio de termociclagem, uma vez que o material não estava adequadamente retido na superfície do material restaurador. O que se observa para esse material restaurador, enfim, é que a proteção superficial com cianoacrilato precedida de ataque ácido supera, em grande parte, a ocorrência de infiltração marginal (Grupo 3).

Em relação ao cimento de ionômero de vidro, observou-se que sua capacidade de adesão à estrutura dentária influenciou na redução da infiltração marginal mais do que o uso do agente de proteção, uma vez que a infiltração apresentada no grupo controle foi estatisticamente semelhante à apresentada pelos grupos em que houve aplicação do cianoacrilato $(\mathrm{p}<0,05)$. Esta capacidade constitui uma das principais vantagens dos cimentos de ionômero de vidro e se dá pela reação dos grupos carboxílicos dos poliácidos com o cálcio do dente, resultando numa verdadeira união química (ANUSAVICE², 1998; CONCEIÇÃO ${ }^{14}, 2000$ ). Nesse caso, os agentes de proteção superficial teriam como função principal evitar a sinérese e embebição desses materiais, sendo este procedimento altamente recomendado pela literatura (ANUSAVICE ${ }^{2}, 1998$ ). Além disso, os cimentos de ionômero de vidro possuem coeficiente de expansão térmica semelhante ao do dente, o que promove menor tensão na interface dente/restauração e, conseqüentemente, menor infiltração (HICKEL \& FOLWACZNY ${ }^{22}$, 2001; HSE et al. $\left.{ }^{23}, 1999\right)$.

Um achado interessante, analisando-se os resultados, foi que a aplicação do cianoacrilato após condicionamento ácido foi mais efetiva no cimento de óxido de zinco e eugenol $(0,2)$ do que no cimento de ionômero de vidro $(1,0)$ apesar de não haver diferença estatística entre eles. Isso pode ser explicado pela diminuição da adesão do cimento de ionômero de vidro à estrutura dental causada pela ação do ácido fosfórico sobre as partículas de vidro do ionômero. Dessa forma, a adesão química ficou prejudicada e o material tornou-se mais poroso. O cianoacrilato aplicado foi utilizado não somente para preencher as irregularidades criadas pelo ácido fosfórico no esmalte dental e proteger a margem da restauração. Pode também ter sido consumido no preenchimento dos poros criados no vidro do ionômero. Assim, uma maior quantidade de material protetor seria necessário para que a proteção fosse mais efetiva.

Já com o cimento de óxido de zinco, a aplicação do ácido fosfórico possivelmente proporcionou a formação de fosfato de zinco que, precipitado, pode ter ajudado na proteção das margens da restauração, o que seria traduzido, então pela menor infiltração.

\section{Conclusão}

De acordo com a metodologia empregada e com os resultados obtidos, conclui-se que a aplicação de cianoacrilato precedida de ataque ácido é um procedimento eficiente para reduzir a infiltração em restaurações de cimento do óxido de zinco e eugenol reforçado. Já para as restaurações de cimento de ionômero de vidro, a utilização de cianoacrilato não influi na proteção contra a infiltração marginal. 


\begin{abstract}
This work had the goal to assess the marginal infiltration in zinc oxide-eugenol cement and glass ionomer cement restorations with and without the use of a surface sealant with a cyanoacrylate base. Thirty posterior teeth were restored with zinc oxide-eugenol cement, ZOE, (15) or with glass ionomer cement, GIC, (15). For each material, the teeth were divided into the following groups: control (5); surface protection with cyanoacrylate preceded by acid etching (5); and surface protection with cyanoacrylate without acid etching. After thermal cycling, the teeth's root surfaces were isolated with Araldite ${ }^{\circledR}$ and the samples were immersed in the staining solution Rodamina B $0.2 \%$. The samples were kept in an oven at $37^{\circ} \mathrm{C}$ for 24 hours and then removed from the staining solution and washed in running water. The teeth were embedded in polyester resin and sectioned in a mesio-distal direction along the long axis. The marginal penetration degree was assessed by means of optic microscopy according to the previous score and the statistically analyzed obtained results (ANOVA-Tukey $p<0.05)$. The ZOE restorations showed reduced marginal infiltration when submitted to surface protection with cyanoacrylate after acid etching. Cyanoacrylate did not reduce the marginal infiltration of GIC restorations.
\end{abstract}

\title{
UNITERMS
}

Cyanoacrylates; pit and fissure; sealants; zinc-eugenol, cement, glass-ionomer cements; dental materials, comparative study

\section{REFERÊNCIAS}

1. Ajlouni R, Bishara SE, Oonsombat C. Effect of water storage on the shear bond strength of a cyanoacrylate adhesive: clinical implications. World J Orthod. 2004; 5(3):250-3.

2. Anusavice KJ. Phillips: Materiais dentários. $10^{\mathrm{a}}$ ed. Rio de Janeiro: Guanabara Koogan; 1998. Cap. 5.

3. Araújo FB, Figueiredo MC. Promoção de Saúde em Odontopediatria. In: Krieger L. (coord.) Promoção de saúde bucal. 2. ed. São Paulo: Artes Médicas; 1999. p.283-348.

4. Azevedo CL, Marques MM, Bombana AC. Cytotoxic effects of cyanoacrylates used as retrograde filling materials: an in vitro analysis. Pesq Odontol Bras. 2003; 17(2):113-8.

5. Barkhordar RA, Javid B, Abbasi J, Watanabe LG. Cyanoacrylate as a retrofilling material. Oral Surg Oral Med Oral Pathol. 1988; 65(4):468-73.

6. Barlattani A, Gargari M, Condo S. Cyanoacrylates as a cementation material in fixed prosthodontics. Dent Cadmos. 1991 july. 15; 59(12):66-70.

7. Bhaskar SN, Frisch J. Use of cyanoacrylate adhesives in dentistry. J Am Dent Assoc. 1968; 77:831-7.

8. Bishara SE, Ajlouni R, Oonsombat C, Laffoon J. Bonding orthodontic brackets to porcelain using different adhesives/enamel conditioners: a comparative study. World J Orthod. 2005; 6(1):17-24.

9. Bocca M, Coscia D, Bottalico L, Delpiano IM. New suture techniques in oral surgery. Description and comparison with traditional sutures. Minerva Stomatol. 1999; 48(12):633-7.

10. Borchers L, Tavassol F, Tschernitschek H. Surface quality achieved by polishing and by varnishing of temporary crown and fixed partial denture resins. J Prosthet Dent. 1999;82(5):550-6.

11. Brännstrom $M$, Nyborg $H$. The presence of bacteria in cavities filled with silicate cement and composite resin materials. Sweed Dent J. 1971; 64:149.

12. Campagni WV, Prince J, Defreese C. Measurement of coating agents used for surface protection of stone dies. J Prosthet Dent. 1986; 55(4):470-4.

13. Chong BS, Pitt Ford TR, Watson TF, Wilson RF. Sealing ability of potential retrograde root filling materials. Endod Dent Traumatol. 1995; 11(6):264-9.

14. Conceição EN. Aplicações clínicas dos materiais ionoméricos. In:__. Dentística: saúde e estética. Porto Alegre: Artmed.; 2000. Cap. 10.
15. Corona SAM, Borsatto MC, Palma-Dibb RG, Ramos RP, Pécora JD. . Microleakage on class $\mathrm{V}$ composite restorations after bur, air-abrasion and Er:YAG laser preparation. Oper Dent. 2001; 26 (5):491-7.

16. Cox FC et al. Biocompatibility of surface-sealed dental materials against exposed pulps. J Prosthet Dent. 1987; 57(1):1-8.

17. Dickinson GL, Leinfelder KF, Mazer RB, Russel CM. Effect of surface penetrating sealant on wear rate of posterior composite resin. J Am Dent Assoc. 1990; 121:251-5.

18. Firedman S, Moshonov J, Trope M. Resistance to vertical fracture of roots, previously fractured and bonded with glass ionomer cement, composite resin and cyanoacrylate cement. Endod Dent Traumatol. 1993; 9(3):101-5.

19. Grisdale J. The use of cyanoacrylates in periodontal therapy. J Can Dent Assoc. 1998; 64(9):632-3.

20. Guzman-Armstrong S, Mitchell RJ. Surface coating and leakage of dentin-bonded resin composite restorations. J Dent. 2002; 30(23):113-8.

21. Herod EL. Cyanoacrylates in dentistry: a review of the literature. J Can Dent Assoc. 1990; 56(4):331-4.

22. Hickel RA, Folwaczny M. Various forms of glass ionomers and compomers. Oper Dent. 2001; Supl 6:177-90.

23. Hse KMY, Leung SK, Wei SHY. Resin ionomer restorative materials for children: a review. Aust Dent J. 1999; 44(1): 1-11.

24. Kulkarni SS, Chava VK. Comparison of cyanoacrylate and silk sutures on healing of oral wounds--an animal model study. Indian J Dent Res. 2003; 14(4):254-8.

25. Lambert RL Retentive properties of stainless steel pins cemented with ethyl cyanoacrylate. J Prosthet Dent. 1975; 34(2):187-91.

26. Lopes-Silva AM, Lage-Marques JL. Evaluation of the permeability of the furcation area of deciduous molars conditioned with Er:YAG laser and cyanoacrylate. Pesq Odontol Bras. 2003; 17(3):212-6.

27. Messi G, Marchi AG. Evaluation of skin laceration repair by tissue adhesive in the pediatric emergency room. Panminerva Med. 1992; 34:77-80.

28. Mondelli J, Ishikiriama A, Francischone CE, Navarro MFL, Galan J. Dentística restauradora. Tratamentos clínicos integrados. São Paulo: Pancast. 1990. 484p.

29. Montanaro L, Arrciola CR, Cenni E, Ciapetti G, Savioli F, Filippini F, et al. Cytotoxicity, blood compatibility and antimicrobial activity of two cyanoacrylate glues for surgical use. Biomaterials. 2001; 22:59-66.

30. Morinaga K, Nakagawa K, Carr GB. Tissue reactions after intraosseous implantation of three retrofilling materials. Bull Tokyo Dent Coll. 2003; 44(1):1-7. 
CIANOACRILATO COMO PROTETOR SUPERFICIAL DE RESTAURAÇÕES DE CIMENTO DE ÓXIDO DE ZINCO E EUGENOL

E DE CIMENTO DE IONÔMERO DE VIDRO: AVALIAÇÃO DA INFILTRAÇÃO MARGINAL

31. Perez M, Fernandez I, Marquez D, Bretanha RM. Use of N- butyl -2- cyanoacrylate in oral surgery: biological and clinical evaluation. Artif Organs. 2000; 24(3):241-3

32. Quinn J, Wells G, Sutchliffe T, Jarmuske M, Maw J, Johns P. A randomized trial comparing octylcyanoacrylate tissue adhesive and sutures in the management of lacerations. J Am Med Assoc. 1997; 277:1527-30

33. Thumwanit V, Kedjarune U. Cytotoxicity of polymerized commercial cyanoacrylate adhesive on cultured human oral fibroblasts. Aust Dent J. 1999; 44(4):248-52.

34. Usumez A, Ozturk AN, Aykent F. The effect of dentin desensitizers on thermal changes in the pulp chamber during fabrication of provisional restorations. J Oral Rehabil. 2004; 31(6):579-84
35. Wilson AD, Batchelor RF. Zinc Oxide-Eugenol cements: II. Study of erosion and disintegration. J Dent Res. 1970; 49(3):593-8.

Recebido em: 22/07/05

Aprovado em: 25/10/05

Fernanda de Carvalho Panzeri Pires-de-Souza Faculdade de Odontologia de Ribeirão Preto - USP Av do Café, s/n - Campus Universitário - Monte Alegre

Ribeirão Preto - SP 14040-904

Tel:16-36024081 - Fax:16-39173384 ferpanzeri@forp.usp.br 